\title{
Granulocyte-macrophage colony-stimulating factor-dependent CD11c- positive cells differentiate into active osteoclasts
}

Ruef Nina ${ }^{1,2}$, Silvia Dolder ${ }^{1}$, Daniel Aeberli ${ }^{3}$, Michal Seitz ${ }^{3}$, Deepak Balani ${ }^{4}$, Willy Hofstetter ${ }^{1,2 *}$

${ }^{1}$ Bone Biology \& Orthopaedic Research, Department Clinical Research, University of Bern, Bern, Switzerland

${ }^{2}$ Graduate School for Cellular and Biomedical Sciences, University of Bern, Bern, Switzerland

${ }^{3}$ Department of Rheumatology, Immunology and Allergology, Bern University Hospital, Bern, Switzerland

${ }^{4}$ Department of Medicine, Massachusetts General Hospital, Boston MA, USA

* Corresponding author: Willy Hofstetter

Bone Biology \& Orthopaedic Research

Department of Clinical Research

University of Bern

Murtenstrasse 35

3008 Bern

Switzerland

+41316328786

hofstetter@dkf.unibe.ch 


\section{Abstract}

Levels of circulating cytokines are elevated in inflammatory diseases. Previously, it was shown that interleukin (IL-)17A, in synergism with 1,25-dihydroxyvitamin $D_{3}$

$\left[1,25(\mathrm{OH})_{2} \mathrm{D}_{3}\right]$ and tumor necrosis factor $\alpha(\mathrm{TNF} \alpha)$, induces the release of granulocytemacrophage colony-stimulating factor (GM-CSF) by murine osteoblasts in vitro. In this study, we further analyzed the effects of GM-CSF on osteoclast development in vitro. The effects of IL-17A, TNFa, and $1,25(\mathrm{OH})_{2} \mathrm{D}_{3}$ on the regulation of osteoclast development were investigated in cocultures of bone marrow-derived osteoclast progenitor cells (OPC) and mouse calvarial osteoblasts. Additionally, OPC were grown for 3 days in media containing macrophage colony-stimulating factor (M-CSF), GM-CSF, or M-CSF/GM-CSF. Subsequently, the osteoclastogenic potential and the capacity to dissolve amorphous calcium phosphate were assessed in each of the three populations of OPC.

IL-17A, in synergism with TNFa and $1,25(\mathrm{OH})_{2} \mathrm{D}_{3}$, inhibited the development of osteoclasts in cocultures by stimulating the osteoblast lineage cells to release GM-CSF. GM-CSF-treated OPC expressed traits characteristic of dendritic cells. Upon removal of GM-CSF and supplementation of the culture media with M-CSF/ RANKL, the cells lost their dendritic cell characteristics and differentiated into osteoclasts. OPC pretreated with GM-CSF and M-CSF/GM-CSF exhibited delayed development to osteoclasts and an extended proliferation phase.

Elevated levels of GM-CSF in systemic inflammatory diseases may cause an expansion of the OPC pools in the bone, bone marrow, and blood. Upon homing to the bone, this may lead to an increase in the number of osteoclasts and in bone resorption. 


\section{Keywords}

GM-CSF; Osteoclastogenesis; CD11c; Inflammation 


\section{Introduction}

Rheumatoid arthritis (RA) is an inflammatory disease of the human skeleton. The imbalance between pro- and anti-inflammatory cytokines in affected joints leads to infiltration of the synovium by immune cells, cartilage damage, and loss of subchondral bone. These bone erosions are governed by pro-inflammatory cytokines, which shift the balance between osteoblastic and osteoclastic activities towards resorption [1, 2]. Osteoclasts are multinucleated cells of haematopoietic origin and form by fusion of monocyte/macrophage lineage progenitor cells. Two growth factors, the haematopoietic growth factor macrophage colony-stimulating factor (M-CSF) and receptor activator of nuclear factor $\mathrm{\kappa B}$ ligand (RANKL), are essential and sufficient for osteoclastogenesis. RANKL binds to RANK on the surface of haematopoietic progenitor cells, activating a signal cascade through tumor necrosis factor receptor-associated factors (TRAFs) that leads to the downstream activation of inhibitor of NF-KB kinase (IKK), c-Jun N-terminal kinase (JNK), p38, extracellular signal-regulated kinase (ERK), and Src [2]. Binding of RANKL to RANK is blocked by osteoprotegerin (OPG), a decoy receptor for RANKL. Physiologically, the RANKL:OPG ratio governs the biological efficacy of RANKL and its action on osteoclastogenesis. Besides M-CSF and RANKL, numerous cytokines, such as tumor necrosis factor alpha (TNFa), contribute to the modulation of osteoclast development. TNFa stimulates osteoclast differentiation indirectly by modulating the RANKL and OPG levels in stromal cells and directly by acting on osteoclast progenitor cells (OPC) in synergism with RANKL [3, 4]. In vitro, osteoclasts differentiate from bone marrow cells $(\mathrm{BMC})$ grown in culture media supplemented with M-CSF and RANKL, or in coculture of BMC or OPC and osteoblast lineage cells. Upon stimulation with 1,25- 
dihydroxyvitamin $D_{3}\left[1,25(\mathrm{OH})_{2} D_{3}\right]$, RANKL is upregulated in mesenchymal cells, while OPG levels are attenuated $[5,6]$.

Within the microenvironment of the bone marrow, immune cells interact with bone cells to modulate their differentiation and activity. In the inflamed joints of patients with RA, activated T-cells secrete osteoclastogenic cytokines, including soluble RANKL, TNFa, interleukin (IL-) 6, granulocyte-macrophage colony stimulating factor (GM-CSF), and IL17A $[1,7,8]$. Furthermore, T-cells trigger macrophages, fibroblasts, and endothelial cells to release pro-inflammatory cytokines, leading to elevated levels in the synovial fluid [911]. TNFa, IL-1, and IL-17A are targeted in RA therapies [11]; inhibitory antibodies against these cytokines and combinations thereof attenuate both synovial inflammation and subchondral bone resorption $[12,13]$.

TNF $\alpha$ and IL-17A are potent inducers of GM-CSF release by mesenchymal cells $[14$, 15]. GM-CSF is a member of the family of haematopoietic growth factors, which were originally identified by their capacity to induce the formation of granulocyte and macrophage colonies in vitro $[16,17]$. M-CSF and GM-CSF control the proliferation, differentiation, activation, and survival of monocyte/macrophage lineage cells [17]. Studies on M-CSF-deficient op/op mice demonstrated this factor to control the development of most non-inflammatory macrophage populations and osteoclasts. MCSF-independent macrophages, mainly involved in inflammatory and immune responses, are not affected by the op/op mutation $[18,19]$.

M-CSF is constitutively expressed by multiple cell types and circulates in the blood. GMCSF is not detectable in physiological conditions, but levels rise dramatically during immune response and inflammation [17]. Besides its growth factor-like action on 
granulocytic and macrophage lineage cells, GM-CSF promotes the maturation of dendritic cells, in particular in inflammation [20]. Neutralizing antibodies against GM-CSF have been successfully used in various models to treat autoimmune or inflammatory diseases, including collagen-induced arthritis [17, 21].

In the present study, the roles of IL-17A and GM-CSF in osteoclast differentiation and activity were investigated in vitro, with a focus on the osteoclastogenic potential of OPC exposed to GM-CSF. The data demonstrates that IL-17A, in synergism with TNFa and $1,25(\mathrm{OH})_{2} \mathrm{D}_{3}$, stimulates osteoblasts to release GM-CSF. Exposure of OPC to GM-CSF leads to a dendritic cell-like phenotype. Upon stimulation with M-CSF/RANKL, these cells differentiate into active osteoclasts that are able to dissolve a calcium phosphate (CaP) substrate. 


\section{Materials and Methods}

\subsection{Animals}

Wild-type (wt) C57BI/6J mice and p55TNFR ${ }^{-/ /} / p 75 T N F R^{-/-}$double knockout mice on C57BI/6 J background [22] were bred at the Central Animal Facility of the University of Bern, in compliance with the Swiss guidelines for the care and use of experimental animals. The use of animals in this study was approved by the State Committee for the Control of Animal Experimentation (Bern, $\mathrm{CH}$; permit numbers BE23/13 and BE54/16 to WH).

\subsection{Cell preparations and cultures}

Primary murine osteoblasts were isolated by sequential collagenase digestion of calvariae from 1 to 2 old mice. Briefly, 25 calvariae were digested for $5 \times 20$ min with 3 $\mathrm{mg} / \mathrm{ml}$ collagenase type II (Worthington, NJ, USA) in Hank's balanced salt solution (Sigma-Aldrich, Buchs, $\mathrm{CH}$ ). Fractions containing osteoblasts were pooled and seeded into $75 \mathrm{~cm}^{2}$ culture flasks $\left(10^{6}\right.$ cells/flask) for culture in medium (aMEM; Gibco/LuBio Science, Lucerne, $\mathrm{CH}$ ) supplemented with 10\% fetal bovine serum (FBS; Sigma-Aldrich) and penicillin/streptomycin at $100 \mathrm{U} / \mathrm{ml}$ and $100 \mu \mathrm{g} / \mathrm{ml}$, respectively (Gibco/LuBio Science). After 4 days, the cells were aliquoted $\left(10^{6} \mathrm{cells} / \mathrm{ml}\right)$ and stored in liquid nitrogen. Before the experiments, the cells were expanded in culture medium for 4 days. BMC were obtained from femora and tibiae of 6 to 8 week old $C 57 B / / 6 \mathrm{~J}$ mice. The cells were centrifuged at $250 \times \mathrm{g}$ at $4^{\circ} \mathrm{C}$ for $7 \mathrm{~min}$, and the pellet was resuspended in cell culture medium supplemented with M-CSF ( $30 \mathrm{ng} / \mathrm{ml}$; Chiron, Emeryville, USA) and incubated $\left(37^{\circ} \mathrm{C}\right.$, humidified atmosphere, $\left.5 \% \mathrm{CO}_{2}\right)$ in $75-\mathrm{cm}^{2}$ cell culture flasks $\left(4 \times 10^{6}\right.$ cells/flask). After $24 \mathrm{~h}$, the non-adherent osteoclast progenitor cells (OPC) $\left(3 \times 10^{4}\right.$ 
cells/well) were grown with primary osteoblasts $\left(2 \times 10^{3}\right.$ cells/well) in 48 -well plates. The culture medium was supplemented with $1,25(\mathrm{OH})_{2} \mathrm{D}_{3}\left(10^{-8} \mathrm{M}\right.$; Sigma-Aldrich), recombinant murine TNFa (0.5 ng/ml; Genentech, San Francisco, USA), and IL-17A $(0.1,1,5,10$, or $50 \mathrm{ng} / \mathrm{ml}$; PeproTech, London, UK). Addition of low amounts of TNFa was required to allow for osteoclast development in the cocultures with osteoblasts and OPC from $C 57 B / / 6 \mathrm{~J}$ mice. After 3 days, the medium was replaced, and multinucleated osteoclasts were visible after 4 to 5 days.

Inhibitory antibodies (BD, Allschwil, $\mathrm{CH}$ ) were used to assess the effect of GM-CSF on osteoclastogenesis. Rat anti-mouse antibodies against GM-CSF were added to the cultures at $1 \mu \mathrm{g} / \mathrm{ml}$. Control cultures were treated with isotype controls (rat IgG2a K Isotype Ctrl).

\subsection{Osteoclast development in vitro}

Non-adherent, M-CSF-dependent OPC were seeded into 5-cm petri dishes $\left(2 \times 10^{6}\right.$ cells/dish) and grown in aMEM/10\% FBS supplemented with M-CSF (30 ng/ml), GMCSF $(0.1,1$, or $10 \mathrm{ng} / \mathrm{ml}$; BD), and M-CSF/GM-CSF. After 3 days, the cells were detached by incubating them in $0.02 \%$ EDTA (Applichem, Darmstadt, Germany) in PBS (Dulbecco's phosphate-buffered saline, $\mathrm{pH} 7.4$; Sigma-Aldrich) at $37^{\circ} \mathrm{C}$ for $10 \mathrm{~min}$. The cells were seeded into new culture dishes at a density of $10^{5} \mathrm{cells} / \mathrm{ml}$ and further growin in medium supplemented with M-CSF (30 ng/ml) and RANKL $(20 \mathrm{ng} / \mathrm{ml})$.

\subsection{GM-CSF ELISA}

GM-CSF release was quantitated in the supernatants of cultures treated with IL-17A, TNFa, and $1,25(\mathrm{OH})_{2} \mathrm{D}_{3}$ using a BD OptEIA ${ }^{\mathrm{TM}}$ Mouse GM-CSF ELISA set (BD), 
following the manufacturer's recommendations. The absorption was measured at 450 $\mathrm{nm}$ (690 $\mathrm{nm}$ reference wavelength) on an Infinite 200Pro Spectrophotometer (Tecan Group Ltd., Männedorf, CH).

\subsection{Staining of osteoclast cultures for tartrate-resistant acid phosphatase (TRAP)}

To visualize osteoclasts, cultures were stained for the enzyme TRAP using a commercial kit (Sigma-Aldrich). Before TRAP staining, cultures were fixed with $4 \%$ paraformaldehyde (Merck, Darmstadt, Germany). TRAP-positive, multinucleated cells ( $\geq$ 3 nuclei) were counted as osteoclasts. TRAP activity was quantified in cell lysates. Cells were lysed in $0.1 \%$ Triton $\mathrm{X}-100 / 1 \mathrm{M} \mathrm{NaCl}$ and frozen at $-20^{\circ} \mathrm{C}$. Fifty microliters of paranitro-phenyl-phosphate (Sigma-Aldrich; $4.61 \mathrm{mg} / \mathrm{ml}$ ) was added to $50 \mu \mathrm{l}$ of cell lysate in $40 \mathrm{mM} \mathrm{Na}$-tartrate/50 mM Na-acetate, $\mathrm{pH} 4.8$, and incubated at room temperature. After $25 \mathrm{~min}$, the reaction was stopped with $50 \mu \mathrm{l} 0.2 \mathrm{M} \mathrm{NaOH}$ and absorption was measured at $405 \mathrm{~nm}$ (690 $\mathrm{nm}$ reference wavelength), using an Infinite 200Pro Spectrophotometer.

\subsection{RNA isolation and quantitative reverse-transcription (qRT-)PCR}

Quantitative PCR was used to assess gene expression in cultures treated with IL-17A, TNFa, and $1,25(\mathrm{OH})_{2} \mathrm{D}_{3}$. Total RNA was isolated on day 5 of culture, using a NucleoSpin ${ }^{\circledR}$ RNA Kit (Macherey-Nagel, Oensingen, $\mathrm{CH}$ ), following the manufacturer's recommendations. Total RNA was reverse-transcribed with M-MLV reverse transcriptase (Promega, Dübendorf, $\mathrm{CH}$ ), and with random primers (Promega), nucleotide mix (Roche, Basel, CH), and RNase inhibitors (Roche). PCR was carried out on an ABI7500 System (Applied Biosystems), using Assays-on-Demand (AoD; Applied Biosystems/LuBio Science) and TaqMan ${ }^{\circledR}$ Fast Universal PCR Master Mix (Applied Biosystems). After a denaturing period of $20 \mathrm{~s}$ at $95^{\circ} \mathrm{C}, 45$ amplification cycles of $3 \mathrm{~s}$ at 
$95^{\circ} \mathrm{C}$ and $30 \mathrm{~s}$ at $60^{\circ} \mathrm{C}$ were performed. The following $A \circ D$ were used: osteoclast stimulatory transmembrane protein (OC-STAMP; Mm00512445_m1), dendrocyte expressed seven transmembrane protein (DC-STAMP; Mm04209236_m1), integrin alpha X (CD11c; Mm00498698_m1), colony-stimulating factor 1 receptor (CSF-1R/ cFMS; Mm01266652_m1), colony-stimulating factor 2 receptor, alpha, low-affinity (Csf2ra/ GM-CSF-Ra; Mm00438331_g1), nuclear factor of activated T-cells, cytoplasmic, calcineurin-dependent 1 (Nfatc1; Mm00479445_m1), calcitonin receptor (CTR; Mm00432271_m1), adhesion G protein-coupled receptor E1 (F4/80; Mm00802529_m1), osteoprotegerin (OPG; Mm00435452_m1), receptor activator of NFкB ligand (RANKL; Mm00441908_m1), and for normalization, $\beta$-glucuronidase (GUSB; Mm01197698_m1).

\subsection{Osteoclast activity assay}

The activity of osteoclasts was assessed by their capacity to dissolve amorphous $\mathrm{CaP}$. As described previously [23], sterile-filtered solutions of $0.12 \mathrm{M} \mathrm{Na}_{2} \mathrm{HPO}_{4}$ and $0.2 \mathrm{M}$ $\mathrm{CaCl}_{2}$ in $50 \mathrm{mM} \mathrm{Tris} / \mathrm{HCl}, \mathrm{pH} 7.4$, were left in an atmosphere of $5 \% \mathrm{CO}_{2}$ at $37^{\circ} \mathrm{C}$ overnight. Then, ${ }^{45}[\mathrm{Ca}] \mathrm{Cl}_{2}$ (PerkinElmer, Schwerzenbach, $\mathrm{CH}$ ) was added to a final concentration of $8000 \mathrm{~Bq}$ per well. Equal volumes were mixed in $50 \mathrm{ml}$ tubes and $\mathrm{CaP}$ was precipitated. The slurry was washed with water twice, resuspended with $10 \mathrm{ml}$ of water per $1 \mathrm{ml}$ of slurry, and $200 \mu \mathrm{l}$ of the suspension was transferred into the wells of 48-well plates. The plates were dried at room temperature under sterile conditions for 3 days and then baked at $80^{\circ} \mathrm{C}$ for $3 \mathrm{~h}$. Before use, the CaP layers were coated with aMEM/30\% FBS overnight. Osteoclasts were generated in vitro from OPC as described above. Mature osteoclasts were resuspended in $500 \mu \mathrm{l}$ of medium per dish and seeded 
into the CaP-coated wells (50 $\mu$ l of cell suspension per well) in medium supplemented with M-CSF (30 ng/ml), RANKL (20 ng/ml), and $\mathrm{HCl}(15 \mathrm{mM})$. After $24 \mathrm{~h}$, the supernatants were collected and ${ }^{45}[\mathrm{Ca}]$ was measured. The cells were lysed for measurement of total TRAP activity.

\subsection{Magnet-activated cell sorting (MACS) and flow cytometry}

GM-CSF-dependent progenitor cells $\left(4 \times 10^{8}\right)$ were incubated with anti-CD11c magnetic beads at $4^{\circ} \mathrm{C}$ for $15 \mathrm{~min}$ and loaded onto columns that were placed in a magnetic cell separator (all from Miltenyi Biotech, Bergisch Gladbach, Germany). Positive (adherent) and negative (non-adherent) cell fractions were collected and counted. The individual cell fractions were differentiated into osteoclasts in culture media supplemented with $\mathrm{M}$ CSF/ RANKL as described above ( $10^{5}$ cells $\left./ \mathrm{ml}\right)$. Unsorted cells with and without beads served as controls. To assess the efficiency of the sorting procedure, the cells were analyzed by flow cytometry. After washing of the cells with staining buffer (PBS, $0.02 \%$ sodium azide, 2\% FCS), they were labeled with FITC-conjugated anti-CD11c antibody (BioLegend, San Diego, CA, USA) for 20 min on ice and analyzed in an LSR II SORP (BD). Isotype-matched antibodies (BD) were used as negative controls and $\mathrm{BD}^{\mathrm{TM}}$ CompBeads were used for compensation. Data were analyzed using the FLOWJO software, version 10.

\subsection{EdU proliferation assay.}

To assess proliferation during osteoclast formation from OPC, cells were labeled with the thymidine analogue EdU (5-ethynyl-2'-deoxyuridine). The Click-i $\mathrm{T}^{\circledR}$ EdU Alexa Fluor $^{\circledR} 488$ Imaging Kit (Invitrogen/LuBio Science) was used, following the manufacturer's protocol. OPC were cultured on cover slips, and on days 3 and 4 of 
culture, $2 \mu \mathrm{M}$ EdU was added for $4 \mathrm{~h}$. Thereafter, the medium was replaced with fresh culture medium supplemented with M-CSF/RANKL. Two days later, the cells were fixed and the EdU incorporated into the DNA was fluorescently labeled, following the Click-iT ${ }^{\circledR}$ protocol. Cell nuclei were stained with $5 \mu \mathrm{g} / \mathrm{ml}$ Hoechst 33342 (Sigma-Aldrich) in PBS for 30 min and osteoclasts were visualized by TRAP staining. The percentage of nuclei with incorporated EdU was assessed by counting EdU-positive nuclei and total nuclei within osteoclasts on microphotographs of 6 randomly chosen field of view, summing up to a total area of $8.4 \mathrm{~mm}^{2}$ per cover slip.

\subsection{Statistical analysis}

Differences in osteoclast numbers, mRNA levels, TRAP activity, ${ }^{45} \mathrm{Ca}$ release, and percentages of proliferating nuclei were evaluated by one-way ANOVA, with Bonferroni's post tests using GraphPad Prism Version 7.01 for Windows (GraphPad Software, San Diego, CA, USA). P-values $<0.05$ were considered significant. 


\section{Results}

\subsection{IL-17A in synergism with TNFa inhibits the formation of osteoclasts in cocultures}

To assess the effects of IL-17A, TNFa, $1,25(\mathrm{OH})_{2} \mathrm{D}_{3}$, and various combinations thereof on osteoclast formation in vitro, wt OPC were cocultured with osteoblasts from either wt mice or $p 55 T N F R^{-/-} / p 75 T N F R^{-/-}$mice. In cocultures with $C 57 B I / 6 J$ wt osteoblasts supplemented with $1,25(\mathrm{OH})_{2} \mathrm{D}_{3} / \mathrm{TNFa}$, IL-17A inhibited osteoclastogenesis, reducing the number of osteoclasts by $\geq 90 \%$ at $1 \mathrm{ng} / \mathrm{ml}$. In cocultures with $C 57 B I / 6 \mathrm{~J} w t$ osteoblasts in the absence of TNFa, only few osteoclasts developed, and IL-17A enhanced osteoclast formation significantly by a factor of 6 , reaching approx. $20 \%$ as compared to $1,25(\mathrm{OH})_{2} \mathrm{D}_{3} / \mathrm{TNFa}$ (Fig. 1A). In cocultures with osteoblasts from p55TNFR ${ }^{-/-} /$p75TNFR $^{--}$mice, the inhibitory effect of IL-17A on osteoclast development was largely abolished while the stimulation of osteoclastogenesis in the absence of TNFa was maintained (Fig. 1B).

\subsection{Primary osteoblasts treated with IL-17A maintain an osteoclastogenic environment.}

To assess, whether the inhibition of osteoclast development by IL-17A is mediated through changes in the expression of the components of the RANKL/ OPG system, levels of transcripts encoding RANKL and OPG were determined by RT-PCR after 3 days of culture (Fig. 2). Treatment of the cells with $1,25(\mathrm{OH})_{2} \mathrm{D}_{3}$ led to an increase in the levels of transcripts encoding RANKL (Fig. 2A), while attenuating OPG mRNA levels (Fig. 2B). Exposure of the cells to increasing concentrations of IL-17A caused a further, 
dose-dependent increase in RANKL mRNA levels, but did not affect OPG mRNA expression.

\subsection{Osteoblast-derived GM-CSF is responsible for the decrease in osteoclast formation.}

The release of GM-CSF by primary osteoblasts in response to an exposure to IL-17A

was assessed in cultures grown with $1,25(\mathrm{OH})_{2} \mathrm{D}_{3}\left(10^{-8} \mathrm{M}\right) / \mathrm{TNF} \alpha(0.5 \mathrm{ng} / \mathrm{ml})$. GM-CSF accumulated in the culture supernatant over $72 \mathrm{~h}$ in a time- and dose-dependent manner, and the release was fully blocked by anti-TNFa antibodies (Fig. 3A). To assess the role of osteoblast-derived GM-CSF in osteoclastogenesis, cocultures grown in media supplemented with TNF $\alpha / 1,25(\mathrm{OH})_{2} \mathrm{D}_{3} / \mathrm{IL}-17 \mathrm{~A}$ and with anti-GM-CSF (Fig. 3B) and isotype control antibodies (Fig. 3C) were evaluated for osteoclast formation. Independently of the remaining culture supplements, $1,25(\mathrm{OH})_{2} \mathrm{D}_{3}$ was required for osteoclastogenesis. Anti-GM-CSF antibodies restored osteoclastogenesis in cultures with $1,25(\mathrm{OH})_{2} \mathrm{D}_{3} / \mathrm{TNF} \alpha$, independently of the concentration of IL-17A. In the absence of TNF $\alpha$, IL-17A stimulated the development of osteoclasts. Isotype control antibodies allowed for the inhibition of osteoclastogenesis by IL-17A, but did not affect the stimulation of cell differentiation in the absence of TNF $\alpha$.

\subsection{Characterization of the phenotype of monocyte/macrophage lineage cells exposed to M-CSF, GM-CSF, or M-CSF/GM-CSF}

OPC were cultured with M-CSF $(30 \mathrm{ng} / \mathrm{ml})$, GM-CSF $(0.1,1$, or $10 \mathrm{ng} / \mathrm{ml})$, and combinations of the two growth factors, and phenotypic markers were assessed by qRTPCR. Supplementation of the culture medium with GM-CSF caused a significant decrease in the levels of mRNA encoding the pan-macrophage marker F4/80 (Fig. 4A). 
Transcript levels of the dendritic cell marker CD11c were dose-dependently increased by exogenous GM-CSF, independently of the presence of M-CSF (Fig. 4B). Similar expression patterns were observed for DC-STAMP (Fig. 4C) and OC-STAMP (Fig. 4D). Levels of cFMS mRNA were dose-dependently decreased with increasing concentrations of GM-CSF (Fig. 4E). CSF2R transcripts were upregulated by GM-CSF, while the presence of M-CSF prevented this increase (Fig. 4F). The corresponding $\mathrm{C}_{\mathrm{T}}$ values are shown in supplementary table 1.

\subsection{OPC precultured with M-CSF, GM-CSF, or M-CSF/GM-CSF give rise to osteoclasts}

OPC were cultured with M-CSF (30 ng/ml), GM-CSF (10 ng/ml), or M-CSF/GM-CSF. The potential of the OPC to develop into osteoclasts was assessed by subsequent culture with M-CSF $(30 \mathrm{ng} / \mathrm{ml}) / \mathrm{RANKL}(20 \mathrm{ng} / \mathrm{ml})$. Starting on day 0 of osteoclast culture, cells were collected daily and total RNA was prepared for qRT-PCR.

In M-CSF-treated OPC, F4/80 transcript levels were twofold higher than those in OPC treated with GM-CSF and M-CSF/GM-CSF at day 0 . Thereafter, F4/80 transcript levels decreased before an induction at day 5 of the osteoclast culture (Fig. 5A). OPC pretreated with GM-CSF and M-CSF/GM-CSF were characterized by increased mRNA levels of CD11c (Fig. 5B), DC-STAMP (Fig. 5C), and OC-STAMP (not shown). The respective transcript levels decreased over time upon exposure to M-CSF/RANKL. With the development of osteoclasts, the levels of DC-STAMP and OC-STAMP transcripts rebounded, which was also observed in cultures of OPC pretreated with M-CSF. Expression of transcripts encoding the osteoclast transcription factor NFATc1 (Fig. 5D) preceded the expression of OC markers and the development of OC. CTR mRNA levels 
(Fig. 5E) increased with cell differentiation and correlated with the numbers of osteoclasts (Fig 5F). The corresponding $\mathrm{C}_{\mathrm{T}}$ values are shown in supplementary table 2.

\subsection{Osteoclasts generated from M-CSF, GM-CSF, and M-CSF/GM-CSF-treated OPC dissolve amorphous CaP in vitro}

The capacity of osteoclasts generated from M-CSF, GM-CSF, and M-CSF/GM-CSF dependent OPC to dissolve $\mathrm{CaP}$ mineral was assessed by seeding mature cells onto a layer of ${ }^{45} \mathrm{Ca}$-spiked amorphous CaP (Fig. 6A). Osteoclasts developed faster from MCSF- than from GM-CSF- and M-CSF/GM-CSF-treated OPC (Fig. 6B). Upon transfer of mature OPC onto the CaP layers, TRAP activity was the same in all 3 groups in the cell suspension and after $1 \mathrm{~h}$ of adherence (Fig. 6C). Within $24 \mathrm{~h}$, total TRAP activity from M-CSF-dependent OPC decreased by $20 \%$, while increasing by more than $50 \%$ in cultures of osteoclasts from GM-CSF- and M-CSF/GM-CSF-dependent OPC (Fig. 6C). Cells in the latter cultures released twofold higher amounts of ${ }^{45} \mathrm{Ca}$ than M-CSFdependent OPC (Fig. 6D). Despite the increased dissolution of CaP, the release of ${ }^{45} \mathrm{Ca}$ per TRAP after $24 \mathrm{~h}$ was similar among all osteoclast populations (Fig. 6D).

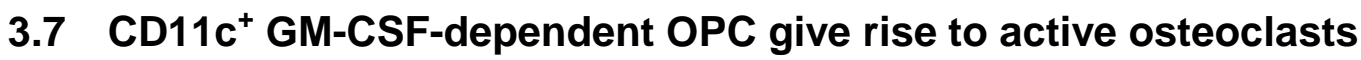

To check whether the $\mathrm{CD} 11 \mathrm{c}^{+}$dendritic-like cells or a $\mathrm{CD} 11 \mathrm{c}^{-}$subpopulation of the GMCSF-dependent OPC give rise to osteoclasts, $\mathrm{CD} 11 \mathrm{c}^{+}$cells were isolated by MACS (CD11 $c^{\text {bright }}$. Unsorted cells, CD11 $\mathrm{c}^{\text {dim }}$, and CD11 $\mathrm{c}^{\text {bright }}$ cells were differentiated into osteoclasts and their capacity to dissolve CaP was assessed. In total GM-CSFdependent OPC (F1) and in control cells with anti-CD11c magnetic beads (F2), approx.

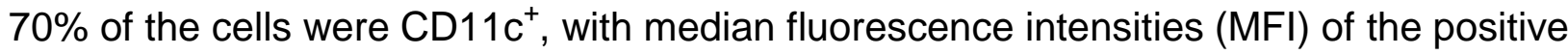
cells at 10,796 and 10,110 respectively. The negatively (flow through) sorted cells were 
$55 \%$ positive (CD11C ${ }^{\text {dim }}$; F3; MFI 6,267), and 98\% of the positively (adherent) sorted

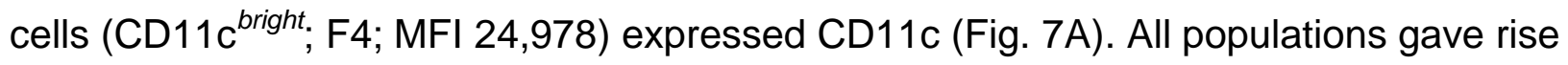
to TRAP-positive, multi-nucleated osteoclasts (Fig. 7B), with similar trends being observed for total TRAP activity (Fig. 7C) and dissolution of CaP mineral (Fig. 7D).

\subsection{Osteoclasts differentiated from GM-CSF-treated progenitors have a higher proliferation potential than those developed from M-CSF-treated progenitors}

To investigate whether the difference in osteoclast development from M-CSF- and GMCSF-dependent OPC is correlated with cell proliferation, the cells were labeled at day 3 and day 4, respectively, with EdU, and nuclear labeling was quantitated after $48 \mathrm{~h}$ at days 5 and 6 of culture. Nuclei were visualized with Hoechst (Fig. 8A,C,E), and mitotic nuclei with EdU (Fig. 8B,D,F). The percentage of labeled nuclei was threefold higher in osteoclasts from GM-CSF- and M-CSF/GM-CSF-dependent OPC than in those from MCSF-dependent OPC after the addition of EdU to the cultures at day 3, and twofold higher when EdU was added at day 4 (Fig. 8G). After six days in culture, the total number of nuclei was doubled in osteoclasts differentiated from OPC dependent on GMCSF and M-CSF/GM-CSF as compared to osteoclasts derived from M-CSF-dependent OPC (Fig. 8H). 


\section{Discussion}

The present study shows that IL-17A, in synergy with TNF $\alpha$ and $1,25(\mathrm{OH})_{2} \mathrm{D}_{3}$, inhibits the formation of osteoclasts in vitro through osteoblast-derived GM-CSF. The growth factor directs OPC differentiation towards a dendritic cell-like phenotype. Upon exposure to M-CSF/RANKL, differentiation towards osteoclasts was delayed in GM-CSFpretreated OPC, allowing proliferation over a longer period, resulting in the expansion of the OPC pools and the development of higher numbers of osteoclasts in vitro.

As in previous studies the coculture system of primary calvaria-derived osteoblast lineage cells and OPC was used for the investigation of osteoclastogenesis [14, 15, 23]. Previously, we found the efficiency of $C 57 B / / 6 J$ derived osteoblast lineage cells to support osteoclast development, however, was low when compared to the efficiency of $d d Y$ osteoblasts $[5,27]$. Only upon supplementation of the culture media with low levels of TNF $\alpha(0.5 \mathrm{ng} / \mathrm{ml})$ the coculture gave rise to osteoclast numbers similar to those of cocultures with $d d Y$ osteoblast lineage cells grown with $1,25(\mathrm{OH})_{2} \mathrm{D}_{3}$ alone (Suppl. Fig. 1). Therefore TNF $\alpha$ was added at $0.5 \mathrm{ng} / \mathrm{ml}$ in every coculture experiment throughout the present study. Furthermore, $d d Y$ osteoblasts were also found to be more efficient in the release of GM-CSF. After 72h, the levels of GM-CSF in the media conditioned by $d d Y$ osteoblasts were $350 \pm 11$ and $104 \pm 6.2 \mathrm{pg} / \mathrm{ml}$, while comparable levels were $75 \pm$ 9.7 and $8.5 \pm 0.9 \mathrm{pg} / \mathrm{ml}$ for $C 57 B / / 6 \mathrm{~J}$ osteoblasts, respectively (Suppl. Fig. 2).

The effects of IL-17A on osteoclastogenesis in vitro are indirect, targeting osteoblast lineage cells in cocultures. The cytokine, together with $1,25(\mathrm{OH})_{2} \mathrm{D}_{3}$, maintains an osteoclastogenic microenvironment by inducing an increase in the levels of transcripts 
encoding RANKL and keeping low levels of OPG mRNA. Simultaneously, IL-17A in synergy with TNFa and $1,25(\mathrm{OH})_{2} \mathrm{D}_{3}$ stimulates the release of GM-CSF, which acts as an inflammatory cytokine $[17,24]$ and an inhibitor of osteoclast development $[14,15$, 25]. By increasing RANKL/OPG ratio, IL-17A stimulates osteoclast formation in cocultures in the absence of TNFa. However, if culture media are supplemented with TNF $\alpha$ and $1,25(\mathrm{OH})_{2} \mathrm{D}_{3}, \mathrm{IL}-17$ induces the release of GM-CSF which overrides any other eventually present pro-osteoclastogenic signals. This specific effect of IL-17A on osteoblast lineage cells contrasts the previously described dual effects of TNFa; inhibiting osteoclast development indirectly by inducing osteoblast lineage cells in synergy with $1,25(\mathrm{OH})_{2} \mathrm{D}_{3}$ to release GM-CSF [14], while stimulating osteoclastogenesis through a direct effect on OPC $[3,4,26,27]$. Haematopoietic growth factors act in sequence on haematopoietic stem cells and, depending on the factor, cells differentiate towards specific lineages $[28,29]$. GM-CSF acts on early progenitor cells and blocks their differentiation towards the monocyte/macrophage and osteoclast lineages [15]. In the presence of GM-CSF, the cells fail to raise levels of RANK, this failure consequently leading to the attenuation of RANK/RANKL signaling. Consequentially, the addition of exogenous RANKL to cocultures could not abrogate the inhibitory effect of GM-CSF. Several studies have shown that the inhibition of osteoclastogenesis by GM-CSF prevents the induction of $c-F o s$ and Fra-1, and indeed, overexpression of c-FOS by retroviral infection rescued osteoclast differentiation despite the presence of GM-CSF $[14,30]$. In a later differentiation stage, characterized by high levels of RANK, GM-CSF no longer affects osteoclastogenesis [15, 25]. 
The second part of the study provides evidence that GM-CSF-dependent OPC express a dendritic cell-like phenotype, characterized by the expression of CD11c and DCSTAMP, but the cells do not undergo an irreversible commitment to the dendritic cell lineage. Upon exposure to M-CSF/RANKL, CD11c and DC-STAMP transcript levels were decreased in GM-CSF-pretreated OPC, before they developed into osteoclasts and reassumed the expression of DC-STAMP.

The effect of GM-CSF on OPC depends on its concentration. In cultures in the presence of GM-CSF in the picogram range, cells remained CD11c', even though differentiation to osteoclasts was blocked [14]. Treatment of OPC with M-CSF and GM-CSF in the nanogram range increased CD11c expression dose-dependently, with a concomitant loss of the pan-macrophage marker F4/80. The concentration-dependent action of GMCSF on haematopoietic cells may be caused by differential activation of signaling pathways, analogous to the action of transforming growth factor $\beta$ (TGF $\beta$ ) on haematopoietic cells [31].

DC-STAMP is required for the regulation of dendritic cell activity and the maintenance of immune self-tolerance [32,33], but it is also present on late OPC and, together with OCSTAMP, participates in cell fusion $[34,35]$. In OPC, levels of DC-STAMP and OCSTAMP transcripts increased in parallel with those of CD11c. In cultures of GM-CSFpretreated OPC, DC-STAMP and OC-STAMP mRNA levels decreased and then increased again with osteoclast maturation. This loss of DC-STAMP and OC-STAMP expression during osteoclast culture indicates that GM-CSF pretreated progenitors first lose their dendritic cell-like phenotype before fusing into multinucleated osteoclasts. Based on the expression of osteoclast transcription factor NFATc1 and on the time 
course of the detection of osteoclasts in culture, osteoclasts from GM-CSF-pretreated OPC do not differ from osteoclasts generated from M-CSF-pretreated OPC, while their differentiation is delayed. This contrasts a recent report postulating that dendritic cells directly fuse to form osteoclasts, so-called DC-OC [36]. However, no specific markers for DC-OC, which would allow distinguishing them from "normal" osteoclasts, are available at present. It has been shown that immature dendritic cells generated from human blood monocytes differentiate into functional osteoclasts in the presence of M-CSF and RANKL [37]. Furthermore, conventional dendritic cells were found to resolve the osteopetrotic phenotype within one month when injected into osteopetrotic oc/oc mice defective in osteoclast resorption [38]. The differentiation mechanisms, however, were not elucidated in these studies, and taking into account the time frame before effects were observed, it is likely that these cells underwent dedifferentiation before developing into osteoclasts.

Osteoclasts from GM-CSF-treated OPC showed the same capacity to dissolve mineral as osteoclasts from M-CSF-treated OPC, but are delayed in differentiation. After transfer onto $\mathrm{CaP}$ at day 5, TRAP activity further increased, which was in contrast to osteoclasts from M-CSF-pretreated OPC, whose number and TRAP activity decreased simultaneously. Thus, osteoclasts from GM-CSF-pretreated progenitors had more time to proliferate in the coculture and to leave the cell cycle at a later time point than did MCSF-pretreated OPC, resulting in a higher number of late progenitors capable of differentiation and fusion. These findings are in accordance with studies demonstrating the proliferative effects of GM-CSF on haematopoietic progenitor cells [39-41]. 
The present study provides evidence for the action of GM-CSF as a positive modulator of osteoclastic activity in the context of inflammatory disease, despite its direct inhibitory effect in vitro on osteoclastogenesis. Furthermore, it confirmed that cells expressing the dendritic cell marker CD11c are not irreversibly committed to the dendritic cell lineage, but can give rise to osteoclasts upon stimulation with M-CSF/RANKL [25, 37, 38].

Osteoclasts and dendritic cells derive from the same myeloid progenitors, and differentiation has been shown to be regulated by M-CSF and GM-CSF [30]. However, as described above, the action of GM-CSF depends on the timing and the differentiation state of the cells, and GM-CSF overrides M-CSF signaling in early haematopoietic progenitors [39]. Besides its systemic effects, GM-CSF secreted by activated T-cells in inflamed joints may also locally increase the number of dendritic cells, which may serve as precursors of osteoclasts and contribute to the exacerbated osteoclastogenesis in RA [42-44].

It has been postulated previously that OPC and osteoclasts may develop and mature in different physical compartments in the organism [14]. In circulation, elevated levels of GM-CSF, as they occur in inflammatory diseases, act by increasing the proliferation of haematopoietic progenitor cells [45]. It was reported that the pool of CD11 $\mathrm{c}^{+}$cells is expanded in RA patients [46, 47]. Upon recruitment to the bone, the composition of the haematopoietic microenvironment changes; RANKL from activated T-cells and osteoblasts takes over and locally induces the development of osteoclasts [7]. 


\section{Acknowledgements}

The authors would like to thank Dr. Antoinette Wetterwald for her support and critical discussions. This work was supported by grants from the Swiss National Science Foundation (NFP64 "Opportunities and risks of nanomaterials," Grant Number 131273) and from the Alfred and Anneliese Sutter-Stöttner Foundation. 


\section{Literature}

[1] I.B. McInnes, G. Schett, Cytokines in the pathogenesis of rheumatoid arthritis, Nat Rev Immunol 7 (2007) 429-442.

[2] W.J. Boyle, W.S. Simonet, D.L. Lacey, Osteoclast differentiation and activation, Nature 423 (2003) 337-342.

[3] K. Kobayashi, N. Takahashi, E. Jimi, N. Udagawa, M. Takami, S. Kotake, N. Nakagawa, M. Kinosaki, K. Yamaguchi, N. Shima, H. Yasuda, T. Morinaga, K. Higashio, T.J. Martin, T. Suda, Tumor necrosis factor $\alpha$ stimulates osteoclast differentiation by a mechanism independent of the Odf/Rankl-Rank interaction, J. Exp. Med. 191 (2000) 275-286.

[4] H. Kitaura, M.S. Sands, K. Aya, P. Zhou, T. Hirayama, B. Uthgenannt, S. Wei, S. Takeshita, D.V. Novack, M.J. Silva, Y. Abu-Amer, F.P. Ross, S.L. Teitelbaum, Marrow stromal cells and osteoclast precursors differentially contribute to TNF- $\alpha$-induced osteoclastogenesis in vivo, The Journal of Immunology 173 (2004) 4838-4846.

[5] N. Takahashi, T. Akatsu, N. Udagawa, T. Sasaki, A. Yamaguchi, J.M. Moseley, T.J. Martin, T. Suda, Osteoblastic cells are involved in osteoclast formation, Endocrinology 123 (1988) 2600-2602.

[6] T. Suda, E. Jimi, I. Nakamura, N. Takahashi, Role of 1 1 ,25-dihydroxyvitamin D3 in osteoclast differentiation and function, Methods Enzymol., Academic Press1997, pp. 223-235.

[7] Y.-Y. Kong, U. Feige, I. Sarosi, B. Bolon, A. Tafuri, S. Morony, C. Capparelli, J. Li, R. Elliott, S. McCabe, T. Wong, G. Campagnuolo, E. Moran, E.R. Bogoch, G. Van, L.T. Nguyen, P.S. Ohashi, D.L. Lacey, E. Fish, W.J. Boyle, J.M. Penninger, Activated T cells regulate bone loss and joint destruction in adjuvant arthritis through osteoprotegerin ligand, Nature 402 (1999) 304-309.

[8] T. Nakashima, H. Takayanagi, Osteoclasts and the immune system, J. Bone Miner. Metab. 27 (2009) 519-529.

[9] S. Kotake, N. Udagawa, N. Takahashi, K. Matsuzaki, K. Itoh, S. Ishiyama, S. Saito, K. Inoue, N. Kamatani, M.T. Gillespie, T.J. Martin, T. Suda, IL-17 in synovial fluids from patients with rheumatoid arthritis is a potent stimulator of osteoclastogenesis, J. Clin. Invest. 103 (1999) 1345-52.

[10] M. Ziolkowska, A. Koc, G. Luszczykiewicz, K. Ksiezopolska-Pietrzak, E. Klimczak, H. ChwalinskaSadowska, W. Maslinski, High levels of IL-17 in rheumatoid arthritis patients: IL-15 triggers in vitro IL-17 production via cyclosporin A-sensitive mechanism, J Immunol. 164 (2000) 2832-8.

[11] G.S. Firestein, Evolving concepts of rheumatoid arthritis, Nature 423 (2003) 356-361.

[12] J. Zwerina, S. Hayer, M. Tohidast-Akrad, H. Bergmeister, K. Redlich, U. Feige, C. Dunstan, G. Kollias, G. Steiner, J. Smolen, G. Schett, Single and combined inhibition of tumor necrosis factor, interleukin-1, 
and RANKL pathways in tumor necrosis factor-induced arthritis: effects on synovial inflammation, bone erosion, and cartilage destruction, Arthritis Rheum. 50 (2004) 277-290.

[13] S. Siebert, A. Tsoukas, J. Robertson, I. McInnes, Cytokines as therapeutic targets in rheumatoid arthritis and other inflammatory diseases, Pharmacol. Rev. 67 (2015) 280-309.

[14] E. Atanga, S. Dolder, T. Dauwalder, A. Wetterwald, W. Hofstetter, TNF $\alpha$ inhibits the development of osteoclasts through osteoblast-derived GM-CSF, Bone 49 (2011) 1090-1100.

[15] D. Balani, D. Aeberli, W. Hofstetter, M. Seitz, Interleukin-17A stimulates granulocyte-macrophage colony-stimulating factor release by murine osteoblasts in the presence of 1,25-dihydroxyvitamin D3 and inhibits murine osteoclast development in vitro, Arthritis Rheum. 65 (2013) 436-446.

[16] D. Metcalf, N.A. Nicola, The clonal proliferation of normal mouse hematopoietic cells: enhancement and suppression by colony-stimulating factor combinations, Blood 79 (1992) 2861-2866.

[17] J.A. Hamilton, Colony-stimulating factors in inflammation and autoimmunity, Nat Rev Immunol 8 (2008) 533-44.

[18] M.G. Cecchini, M.G. Dominguez, S. Mocci, A. Wetterwald, R. Felix, H. Fleisch, O. Chisholm, W. Hofstetter, J.W. Pollard, E.R. Stanley, Role of colony stimulating factor-1 in the establishment and regulation of tissue macrophages during postnatal development of the mouse, Development 120 (1994) 1357-1372.

[19] E.R. Stanley, K.L. Berg, D.B. Einstein, P.S.W. Lee, F.J. Pixley, Y. Wang, Y.-G. Yeung, Biology and action of colony-stimulating factor-1, Mol. Reprod. Dev. 46 (1997) 4-10.

[20] Y. Zhan, Y. Xu, A.M. Lew, The regulation of the development and function of dendritic cell subsets by GM-CSF: more than a hematopoietic growth factor, Mol. Immunol. 52 (2012) 30-37.

[21] A.D. Cook, E.L. Braine, I.K. Campbell, M.J. Rich, J.A. Hamilton, Blockade of collagen-induced arthritis post-onset by antibody to granulocyte-macrophage colony-stimulating factor (GM-CSF): requirement for GM-CSF in the effector phase of disease, Arthritis Res Ther 3 (2001) 1-9.

[22] J. Rothe, W. Lesslauer, H. Lotscher, Y. Lang, P. Koebel, F. Kontgen, A. Althage, R. Zinkernagel, M. Steinmetz, H. Bluethmann, Mice lacking the tumour necrosis factor receptor 1 are resistant to IMFmediated toxicity but highly susceptible to infection by Listeria monocytogenes, Nature 364 (1993) 798802.

[23] W. Xie, S. Lorenz, S. Dolder, W. Hofstetter, Extracellular iron is a modulator of the differentiation of osteoclast lineage cells, Calcif. Tissue Int. 98 (2016) 275-283.

[24] J.A. Hamilton, GM-CSF as a target in inflammatory/autoimmune disease: current evidence and future therapeutic potential, Exp Rev Clin Immunol 11 (2015) 457-465. 
[25] R. Lari, A.J. Fleetwood, P.D. Kitchener, A.D. Cook, D. Pavasovic, P.J. Hertzog, J.A. Hamilton, Macrophage lineage phenotypes and osteoclastogenesis--complexity in the control by GM-CSF and TGFbeta, Bone 40 (2007) 323-36.

[26] J. Lam, S. Takeshita, J.E. Barker, O. Kanagawa, F.P. Ross, S.L. Teitelbaum, TNF- $\alpha$ induces osteoclastogenesis by direct stimulation of macrophages exposed to permissive levels of RANK ligand, J. Clin. Invest. 106 (2000) 1481-1488.

[27] R. Balga, A. Wetterwald, J. Portenier, S. Dolder, C. Mueller, W. Hofstetter, Tumor necrosis factoralpha: alternative role as an inhibitor of osteoclast formation in vitro, Bone 39 (2006) 325-335.

[28] D. Metcalf, The molecular control of cell division, differentiation commitment and maturation in haemopoietic cells, Nature 339 (1989).

[29] D. Metcalf, Hematopoietic regulators: redundancy or subtlety?, Blood 82 (1993) 3515-3523.

[30] T. Miyamoto, O. Ohneda, F. Arai, K. Iwamoto, S. Okada, K. Takagi, D.M. Anderson, T. Suda, Bifurcation of osteoclasts and dendritic cells from common progenitors, Blood. 98 (2001) 2544-54.

[31] V.P. Kale, A.A. Vaidya, Molecular mechanisms behind the dose-dependent differential activation of MAPK pathways induced by transforming growth factor- $\beta 1$ in hematopoietic cells, Stem Cells Dev 13 (2004) 536-547.

[32] Y. Sawatani, T. Miyamoto, S. Nagai, M. Maruya, J. Imai, K. Miyamoto, N. Fujita, K. Ninomiya, T. Suzuki, R. Iwasaki, Y. Toyama, M. Shinohara, S. Koyasu, T. Suda, The role of DC-STAMP in maintenance of immune tolerance through regulation of dendritic cell function, Int. Immunol. 20 (2008) 1259-1268. [33] A. Sanecka, M. Ansems, A.C. Prosser, K. Danielski, K. Warner, M.H. den Brok, B.J.H. Jansen, D. Eleveld-Trancikova, G.J. Adema, DC-STAMP knock-down deregulates cytokine production and T-cell stimulatory capacity of LPS-matured dendritic cells, BMC Immunology 12 (2011) 57-57.

[34] Y.-H. Chiu, C.T. Ritchlin, DC-STAMP: a key regulator in osteoclast differentiation, J. Cell. Physiol. 231 (2016) 2402-2407.

[35] M. Yang, M.J. Birnbaum, C.A. MacKay, A. Mason-Savas, B. Thompson, P.R. Odgren, Osteoclast stimulatory transmembrane protein (OC-STAMP), a novel protein induced by RANKL that promotes osteoclast differentiation, J. Cell. Physiol. 215 (2008) 497-505.

[36] O. Laperine, C. Blin-Wakkach, J. Guicheux, S. Beck-Cormier, P. Lesclous, Dendritic-cell-derived osteoclasts: a new game changer in bone-resorption-associated diseases, Drug Discov Today (2016). [37] A. Rivollier, M. Mazzorana, J. Tebib, M. Piperno, T. Aitsiselmi, C. Rabourdin-Combe, P. Jurdic, C. Servet-Delprat, Immature dendritic cell transdifferentiation into osteoclasts: a novel pathway sustained by the rheumatoid arthritis microenvironment, Blood 104 (2004) 4029-4037. 
[38] A. Wakkach, A. Mansour, R. Dacquin, E. Coste, P. Jurdic, G.F. Carle, C. Blin-Wakkach, Bone marrow microenvironment controls the in vivo differentiation of murine dendritic cells into osteoclasts, Blood 112 (2008) 5074-5083.

[39] J.M. Hodge, M.A. Kirkland, C.J. Aitken, C.M. Waugh, D.E. Myers, C.M. Lopez, B.E. Adams, G.C. Nicholson, Osteoclastic potential of human CFU-GM: biphasic effect of GM-CSF, J. Bone Miner. Res. 19 (2004) 190-199.

[40] W. Liggett, N. Shevde, P. Anklesaria, S. Sohoni, J. Greenberger, J. Glowacki, Effects of macrophage colony stimulating factor and granulocyte-macrophage colony stimulating factor on osteoclastic differentiation of hematopoietic progenitor cells, Stem Cells 11 (1993) 398-411.

[41] C. Menaa, R.D. Devlin, S.V. Reddy, Y. Gazitt, S.J. Choi, G.D. Roodman, Annexin II increases osteoclast formation by stimulating the proliferation of osteoclast precursors in human marrow cultures, J. Clin. Invest. 103 (1999) 1605-1613.

[42] R. Thomas, K.P. MacDonald, A.R. Pettit, L.L. Cavanagh, J. Padmanabha, S. Zehntner, Dendritic cells and the pathogenesis of rheumatoid arthritis, J Leukocyte Biol 66 (1999) 286-92.

[43] J. Highton, A. Kean, P. Hessian, J. Thomson, J. Rietveld, D. Hart, Cells expressing dendritic cell markers are present in the rheumatoid nodule, J. Rheumatol. 27 (2000) 339-46.

[44] F. Santiago-Schwarz, P. Anand, S. Liu, S.E. Carsons, Dendritic cells (DCs) in rheumatoid arthritis (RA): progenitor cells and soluble factors contained in RA synovial fluid yield a subset of myeloid DCs that preferentially activate Th1 inflammatory-type responses, J. Immunol. 167 (2001) 1758-1768.

[45] C. Menaa, N. Kurihara, G.D. Roodman, CFU-GM-derived cells form osteoclasts at a very high efficiency, Biochem. Biophys. Res. Commun. 267 (2000) 943-946.

[46] Y. Kurohori, K. Sato, S. Suzuki, S. Kashiwazaki, Adhesion molecule expression on peripheral blood mononuclear cells in rheumatoid arthritis: positive correlation between the proportion of L-selectin and disease activity, Clin. Rheumatol. 14 (1995) 335-41.

[47] B. Stuhlmüller, T. Häupl, M.M. Hernandez, A. Grützkau, R.J. Kuban, N. Tandon, J.W. Voss, J. Salfeld, R.W. Kinne, G.R. Burmester, CD11c as a transcriptional biomarker to predict response to anti-TNF monotherapy with adalimumab in patients with rheumatoid arthritis, Clin. Pharmacol. Ther. 87 (2010) 311-321. 


\section{Figure Legends}

Figure 1. TNFa is required for IL-17A mediated inhibition of osteoclast formation. Effects of IL-17A, TNFa, and $1,25(\mathrm{OH})_{2} \mathrm{D}_{3}$ on the development of $\mathrm{OC}$ in cocultures of $w t$ OB and OPC. The addition of IL-17A to cultures supplemented with TNFa and $1,25(\mathrm{OH})_{2} \mathrm{D}_{3}$ led to a dose-dependent inhibition of $\mathrm{OC}$ formation. In the absence of TNFa, $1,25(\mathrm{OH})_{2} \mathrm{D}_{3}$-mediated OC formation was stimulated by IL-17A. In the absence of $1,25(\mathrm{OH})_{2} \mathrm{D}_{3}$, no OC did form $(A)$. Effect of IL-17A on the development of OC in cocultures of $p 55 T N F R^{-/ /} / p 75 T N F R^{-/-}$OB and wt OPC. The inhibitory effect of IL-17A in the presence of TNF $\alpha$ and $1,25(\mathrm{OH})_{2} \mathrm{D}_{3}$ was abolished $(\mathrm{B})$. Cultures were stained for TRAP on day 5 and osteoclasts were counted. Bars show the mean $\pm \operatorname{SD}(n=6) .{ }^{*}=$ $p<0.05$ and ${ }^{* *}=p<0.01$; significant differences to respective cultures without IL-17A.

Figure 2. IL-17A maintains a pro-osteoclastogenic phenotype in C57BI/6J mice. Cells were cultured with or without IL-17A, TNFa, and $1,25(\mathrm{OH})_{2} \mathrm{D}_{3}$, total RNA was prepared after 3 days and levels of transcripts encoding RANKL (A) and OPG (B) were determined. Incubation of the cells with $1,25(\mathrm{OH})_{2} \mathrm{D}_{3}$ led to an increase in levels of transcripts encoding RANKL and an attenuation of levels of transcripts encoding OPG. RANKL transcript levels were further elevated dose-dependently by IL-17A, while OPG levels were not affected by IL-17A. The data represents one out of three independent experiments.

Figure 3. Osteoblast derived GM-CSF inhibits osteoclast formation in response to IL-17A. GM-CSF protein levels in the culture supernatants were quantified by ELISA (A). 
Wt OB were cultured with IL-17A at the indicated concentrations in media supplemented with TNFa and 1,25(OH) $)_{2} \mathrm{D}_{3}$ for 2, 4, 8, 24, and $72 \mathrm{~h}$. IL-17A dose-dependently increased the levels of GM-CSF accumulating in the cell culture medium. Addition of anti-TNFa $(1 \mathrm{ng} / \mathrm{ml})$ prevented GM-CSF release. Bars show the mean \pm SD of triplicate cultures. Ab $=$ anti-TNF $\alpha$ antibodies. To assess the role of GM-CSF in the IL-17A mediated inhibition of osteoclast formation, cocultures with primary osteoblasts and OPC were treated with anti-GM-CSF (B) and control (C) antibodies. After 5 days, the cultures were stained for TRAP and osteoclasts were counted. Anti-GM-CSF antibodies restored osteoclastogenesis and allowed for stimulation of osteoclast formation in the absence of TNF $\alpha$ (B). Isotype control antibodies did not affect neither GM-CSF mediated inhibition of osteoclastogenesis nor IL-17A mediated increase in osteoclast number in cultures without TNF $\alpha(C)$. Bars show the mean $\pm \operatorname{SD}(n=6) .{ }^{*}=p<0.05$ and ${ }^{* *}=p<0.01$; significant differences to respective cultures without IL-17A.

Figure 4. Effects of M-CSF, GM-CSF, and M-CSF/GM-CSF on gene expression by OPC. Levels of transcripts coding for F4/80 (A), CD11c (B), DC-STAMP (C), OCSTAMP (D), cFMS (E), and CSF2R (F) were quantitated by qRT-PCR and normalized to levels of transcripts encoding GUSB. GM-CSF dose-dependently upregulated CD11c, a marker for dendritic cells, and downregulated the pan-macrophage marker F4/80. DCSTAMP and OC-STAMP mRNA levels were elevated with increasing doses of GM-CSF. Bars show the mean $\pm S D(n=3) .{ }^{*}=p<0.05$ and ${ }^{*}=p<0.01$. 
Figure 5. OPC, pretreated with M-CSF, GM-CSF, or M-CSF/GM-CSF, give rise to osteoclasts. OPC were cultured with M-CSF (30 ng/ml; white bars), GM-CSF (10 ng/ml; grey bars), or M-CSF/GM-CSF (black bars) for 3 days. The osteoclastogenic potential of the three OPC populations was assessed by culturing the cells in media supplemented with M-CSF/RANKL. Levels of transcripts encoding F4/80 (A), CD11c (B), DC-STAMP (C), NFATc1 (D), and CTR (E) were quantitated and osteoclasts were counted (F). GMCSF, alone or in combination with M-CSF, caused an increase in CD11C and DCSTAMP transcripts. The levels of CD11c and DC-STAMP mRNA decreased gradually after starting M-CSF/RANKL treatment, while DC-STAMP mRNA levels increased again in parallel to osteoclast development, as was observed in M-CSF treated OPC.

Osteoclast formation was delayed in cultures of GM-CSF- and M-CSF/GM-CSF-treated OPC. $(A)-(E)$ : bars show the mean $\pm S D(n=3) ;(F)$ : bars show the mean $\pm S D(n=6)$. ${ }^{*}=p<0.05$ and $^{* *}=p<0.01$; significant differences to respective cultures with OPC pretreated with M-CSF.

Figure 6. Osteoclasts generated from OPC pretreated with M-CSF, GM-CSF, and M-CSF/GM-CSF dissolve amorphous CaP. Osteoclasts on the mineral were stained for TRAP followed by phase-contrast imaging. The resorbed surfaces are visible as bright areas. Scale bar $=100 \mu \mathrm{m}(\mathrm{A})$. Osteoclastogenesis from the OPC populations was followed over time (B). Total TRAP activity was measured after $0 \mathrm{~h}$ (before seeding onto $\mathrm{CaP}$ ), after $1 \mathrm{~h}$ (adhesion), and after $24 \mathrm{~h}$ (C). Release of ${ }^{45} \mathrm{Ca}$ after $24 \mathrm{~h}$ was normalized to total TRAP activity (D). Bars show the mean $\pm \operatorname{SD}(n=6) .{ }^{*}=p<0.05$ and ${ }^{* *}=\mathrm{p}<0.01$; significant differences to respective controls pretreated with M-CSF. 
Figure 7. CD11c-positive cells give rise to osteoclasts. OPC were treated for 3 days with GM-CSF, and CD11 $\mathrm{c}^{+}$cells were sorted by MACS. The potential of the cell fractions (non-sorted, CD11 $\mathrm{c}^{\text {bright }}, \mathrm{CD} 11 \mathrm{c}^{\text {dim) }}$ ) to develop into osteoclasts was assessed by culturing the cells in media supplemented with M-CSF/RANKL. After sorting, the cells were analyzed by flow cytometry. The CD11c ${ }^{\text {bright }}$ were nearly $100 \%$ positive for CD11C. After 5 days, the cells were stained for TRAP (A). All fractions gave rise to osteoclasts (B). Osteoclast development over time was similar for all 4 OPC populations as assessed by total TRAP activity in the cultures (days 3, 4, 5, 6 from white bars to black bars) (C). Release of ${ }^{45} \mathrm{Ca}$, normalized to TRAP activity after $1 \mathrm{~h}$ (white bars), $12 \mathrm{~h}$ (grey bars), and $24 \mathrm{~h}$ (black bars). Osteoclasts from all OPC populations were able to dissolve CaP (D). F1: OPC, F2: unsorted cells, incubated with magnetic beads, F3: CD11 $\mathrm{c}^{\mathrm{dim}}$, F4: CD11 $c^{\text {bright }}$. Bars show the mean $\pm \operatorname{SD}(n=6)$.

Figure 8. Proliferation of OPC pretreated with M-CSF, GM-CSF, and M-CSF/GMCSF during osteoclastogenesis. OPC were precultured with M-CSF (white bars), GMCSF (grey bars), and M-CSF/GM-CSF (black bars) and subsequently grown in media supplemented with M-CSF/RANKL. On days 3 and 4, the cultures were labeled with EdU for $4 \mathrm{~h}$. Two days later, the cultures were stained with Hoechst dye and for EdU. Arrows indicate Hoechst-positive nuclei within osteoclasts, positive or negative for EdU. Scale bar $=100 \mu \mathrm{m}$. M-CSF-pretreated OPC, Hoechst staining and phase contrast (A); M-CSF-pretreated OPC, EdU staining and phase contrast (B); GM-CSF-pretreated OPC, Hoechst staining and phase contrast (C); GM-CSF-pretreated OPC, EdU staining and phase contrast (D); M-CSF/GM-CSF-pretreated OPC, Hoechst staining and phase 
contrast (E); M-CSF/GM-CSF-pretreated OPC, EdU staining and phase contrast $(F)$; Proportion of EdU-positive to total nuclei $(G)$; Total number of nuclei within osteoclasts (H). Six pictures per well were evaluated, corresponding to an area of $8.4 \mathrm{~mm}^{2}$. Bars show the mean \pm SD of triplicate cultures. ${ }^{*}=p<0.05$ and ${ }^{* *}=p<0.01$; significant differences to respective cultures pretreated with M-CSF. 


\section{Figures}

Figure 1
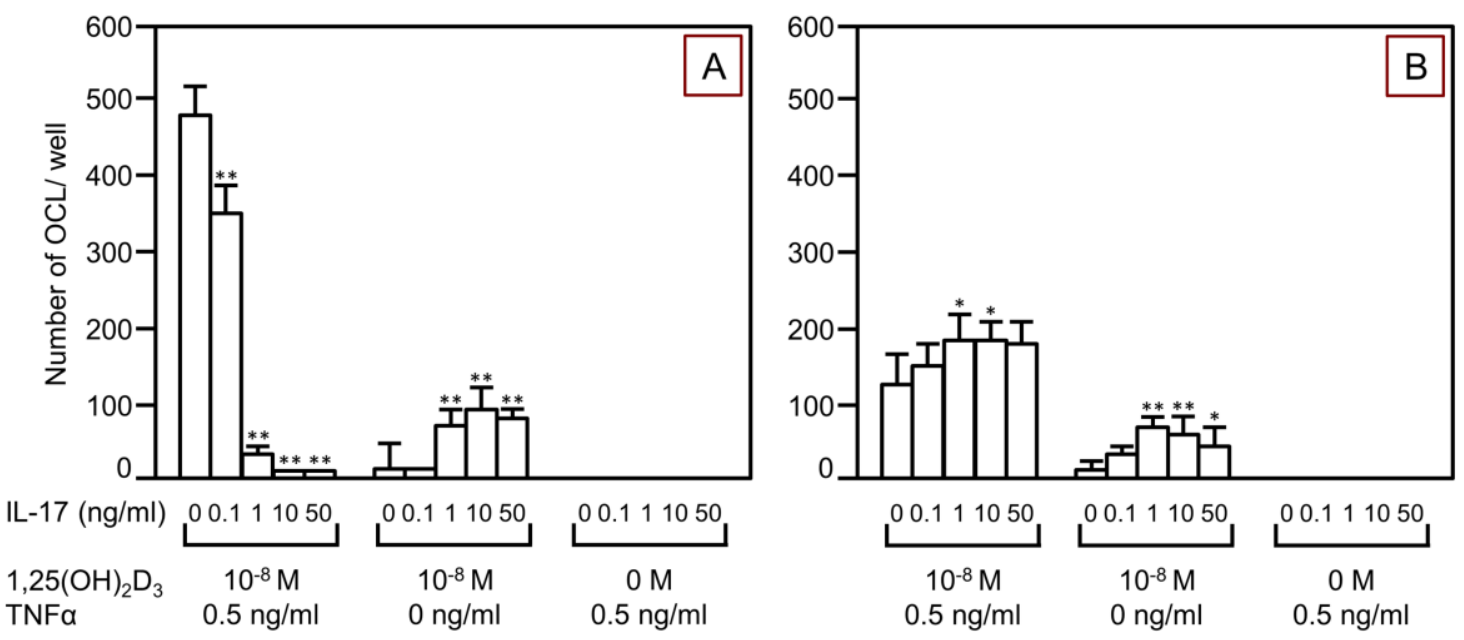
Figure 2
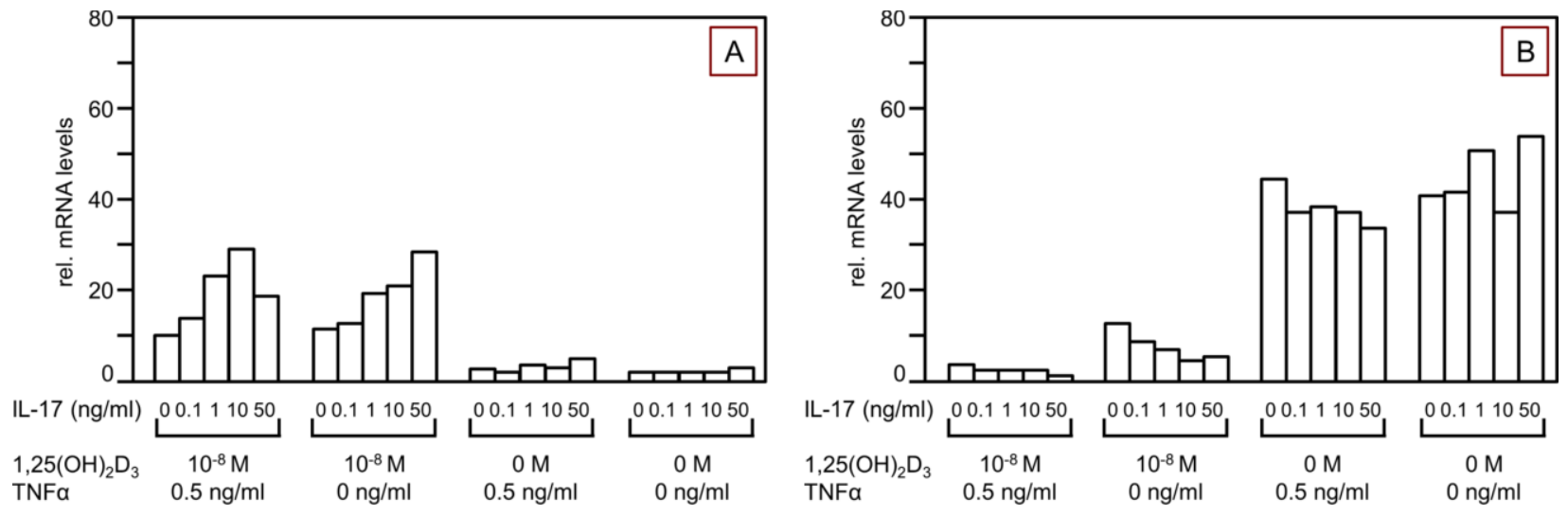
Figure 3

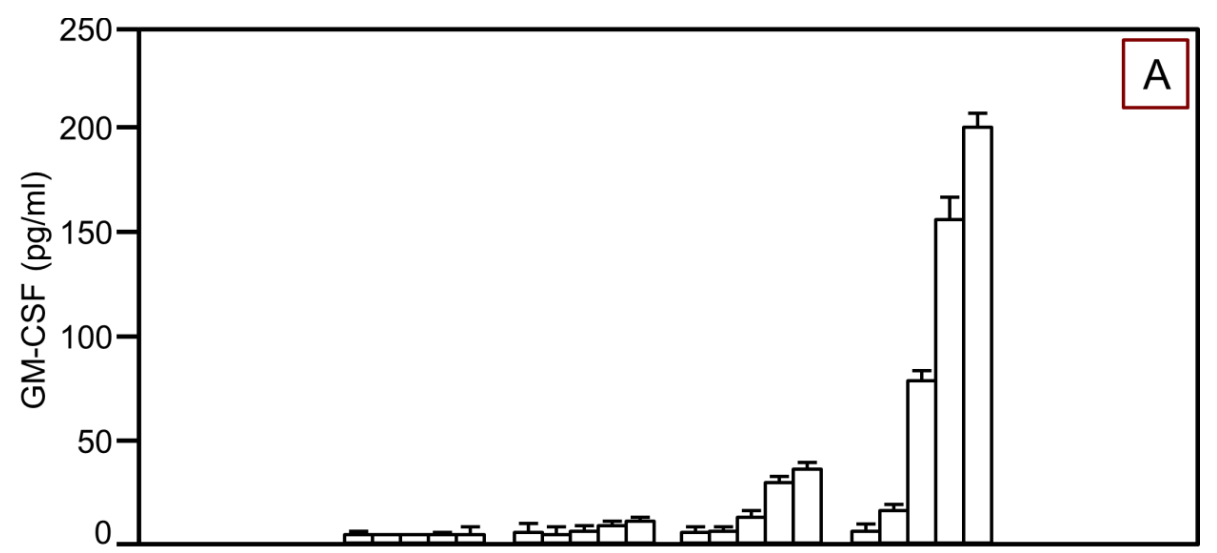

IL-17 (ng/ml)
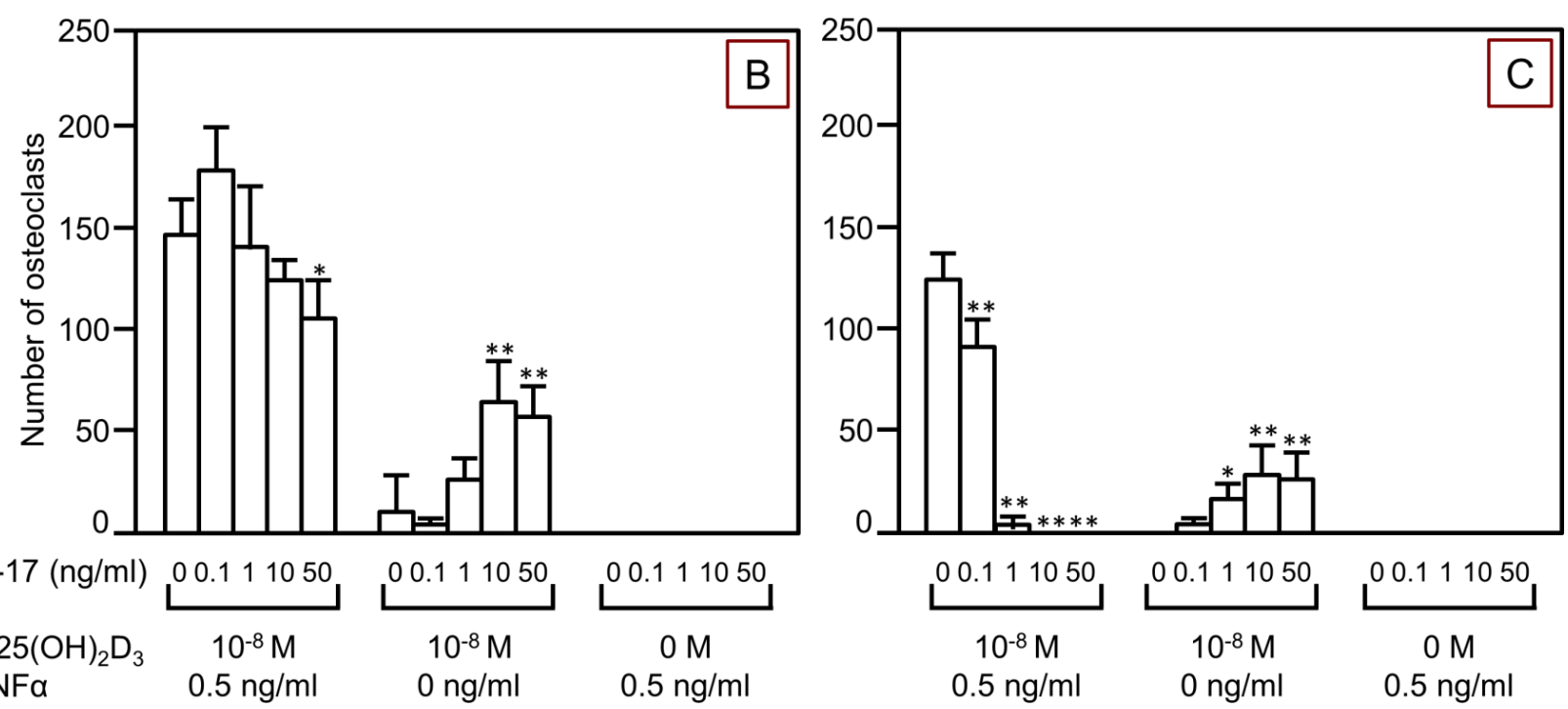
Figure 4
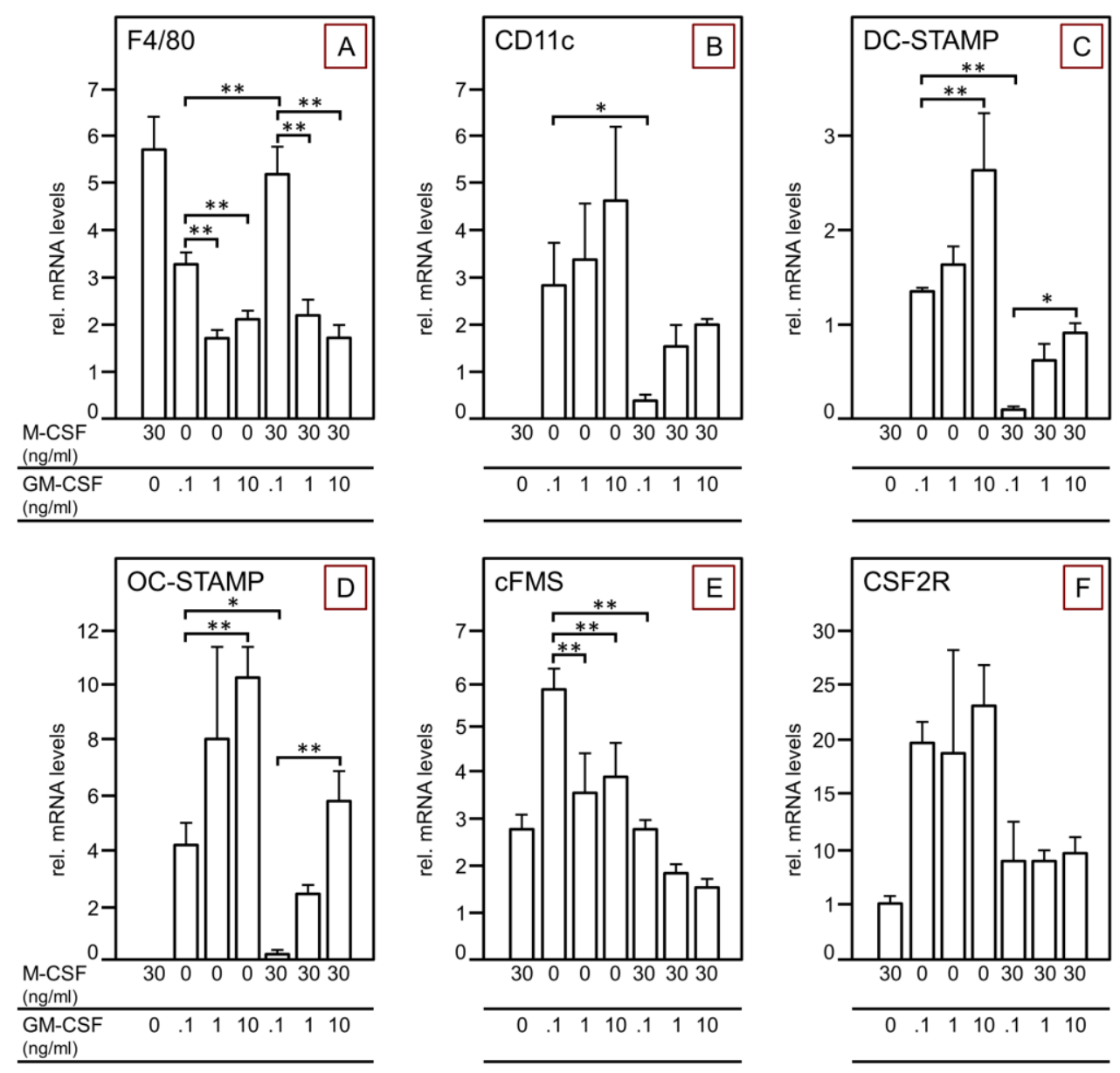
Figure 5
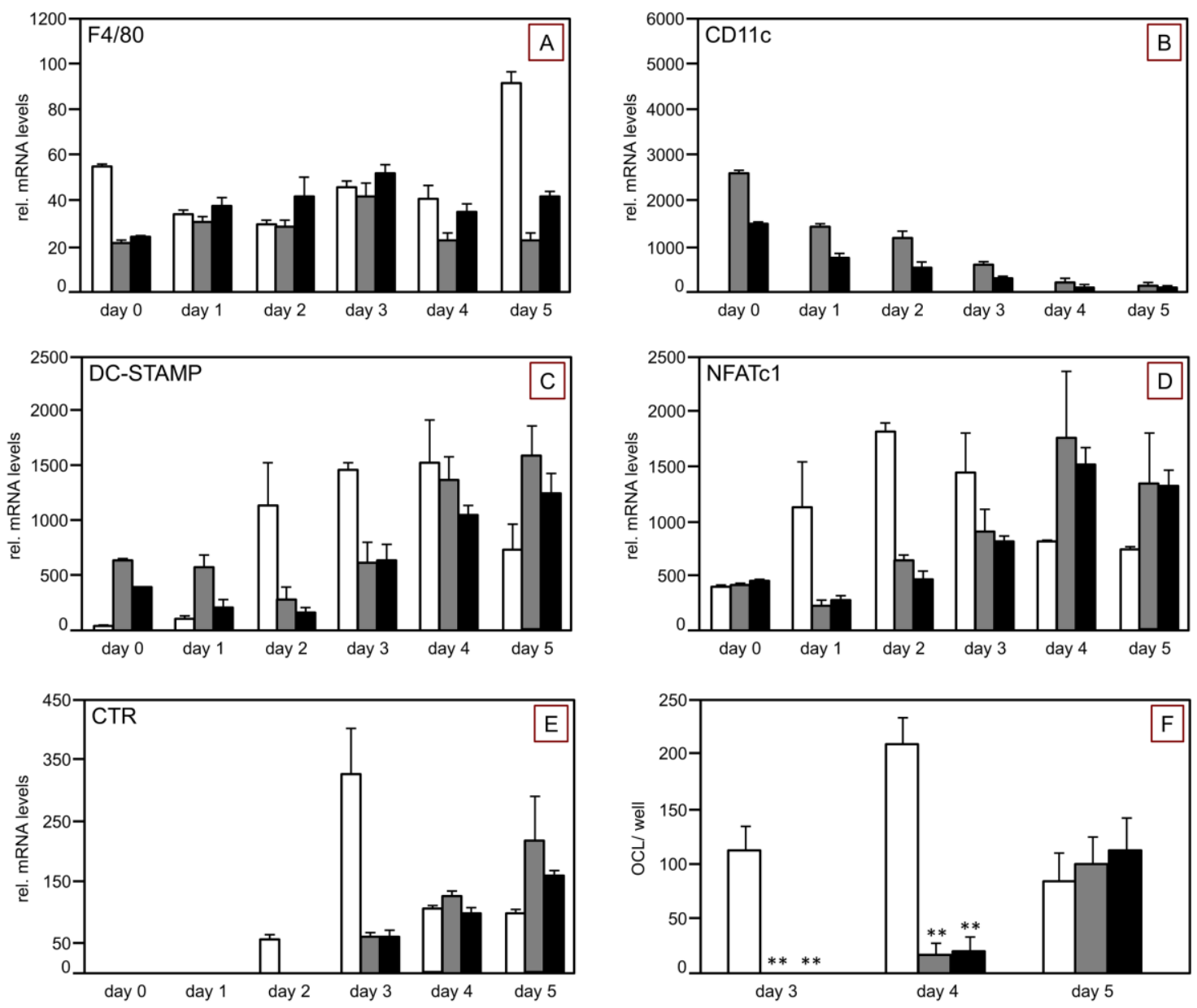
Figure 6
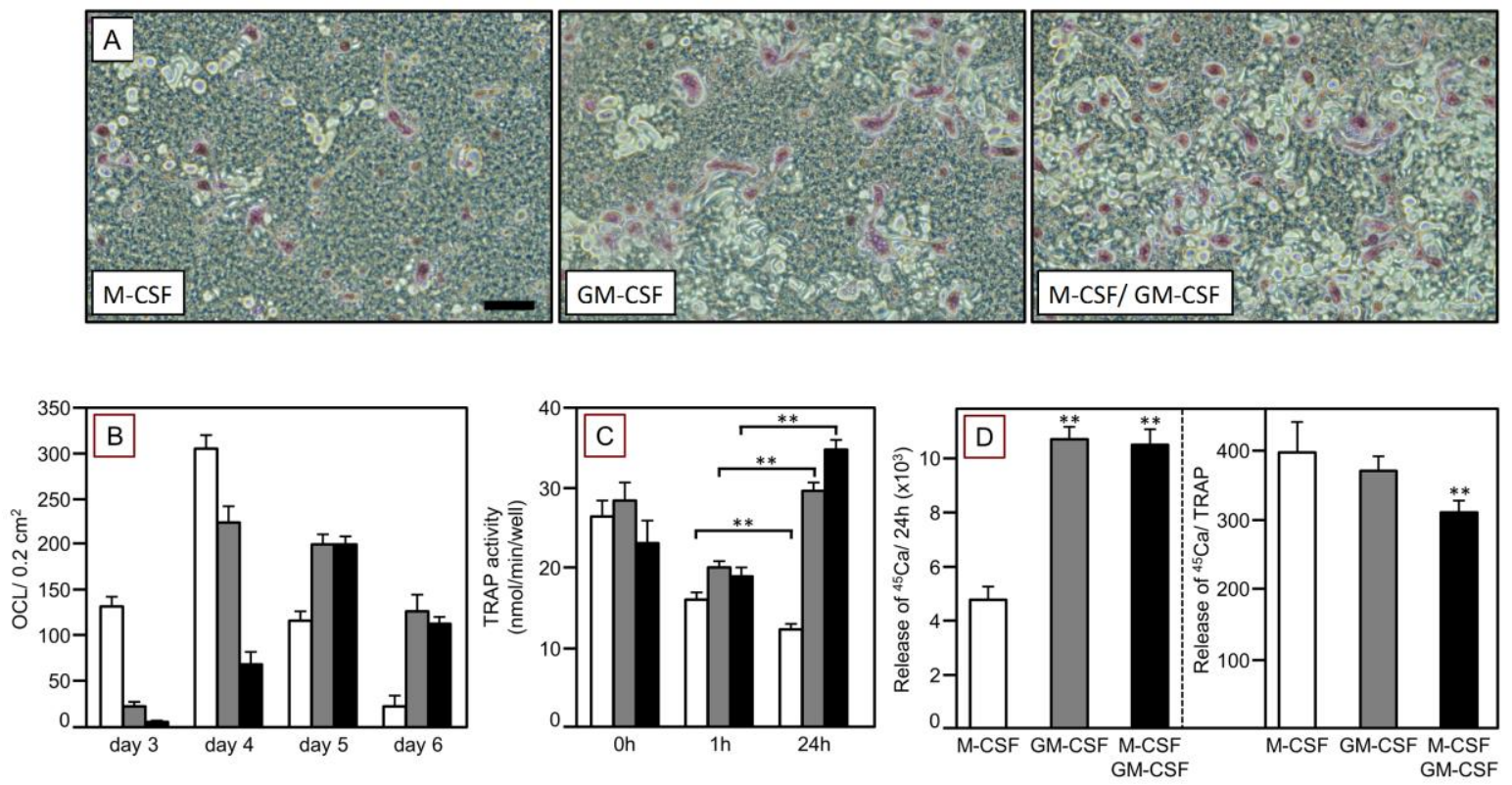
Figure 7
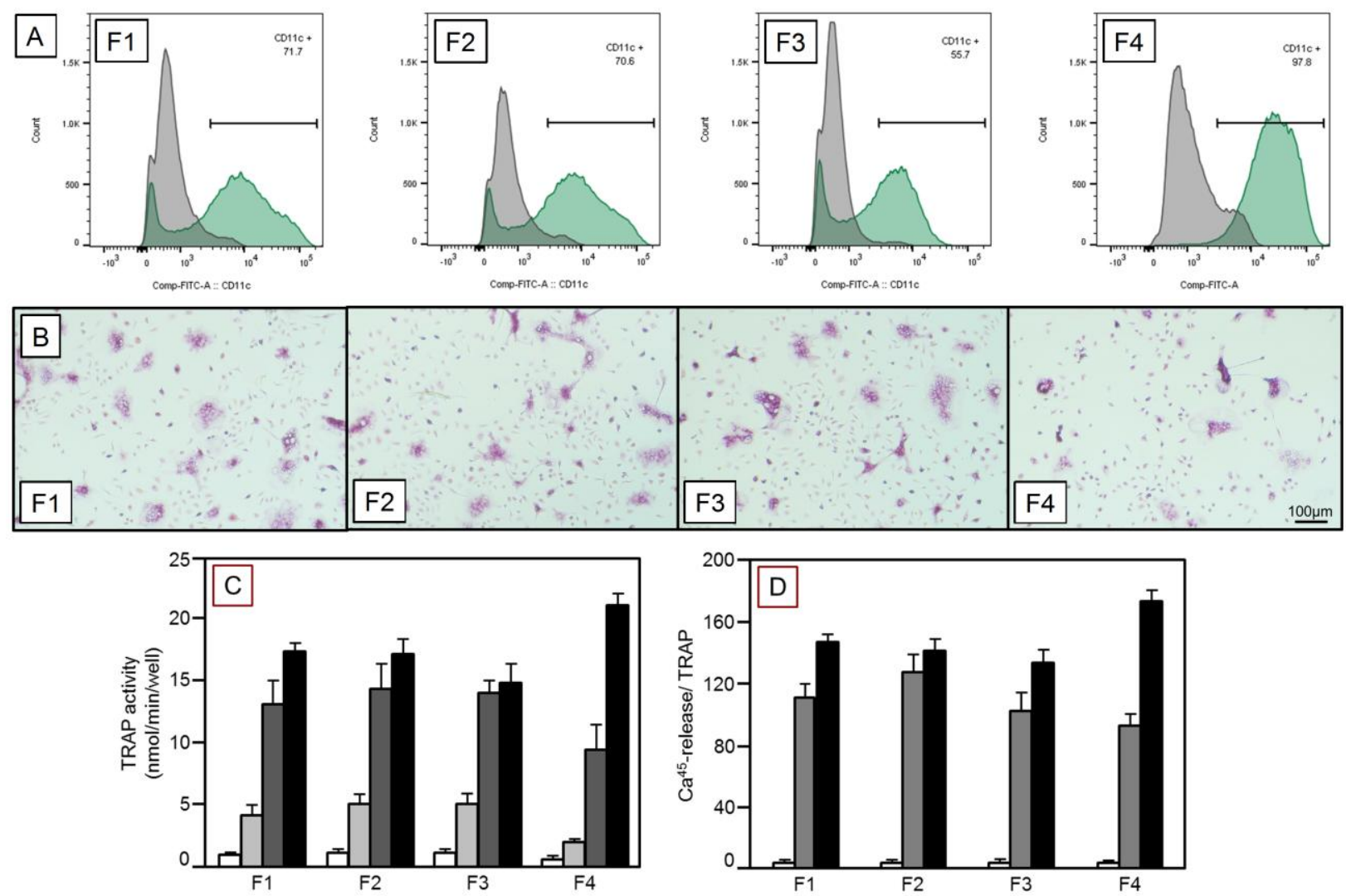
Figure 8
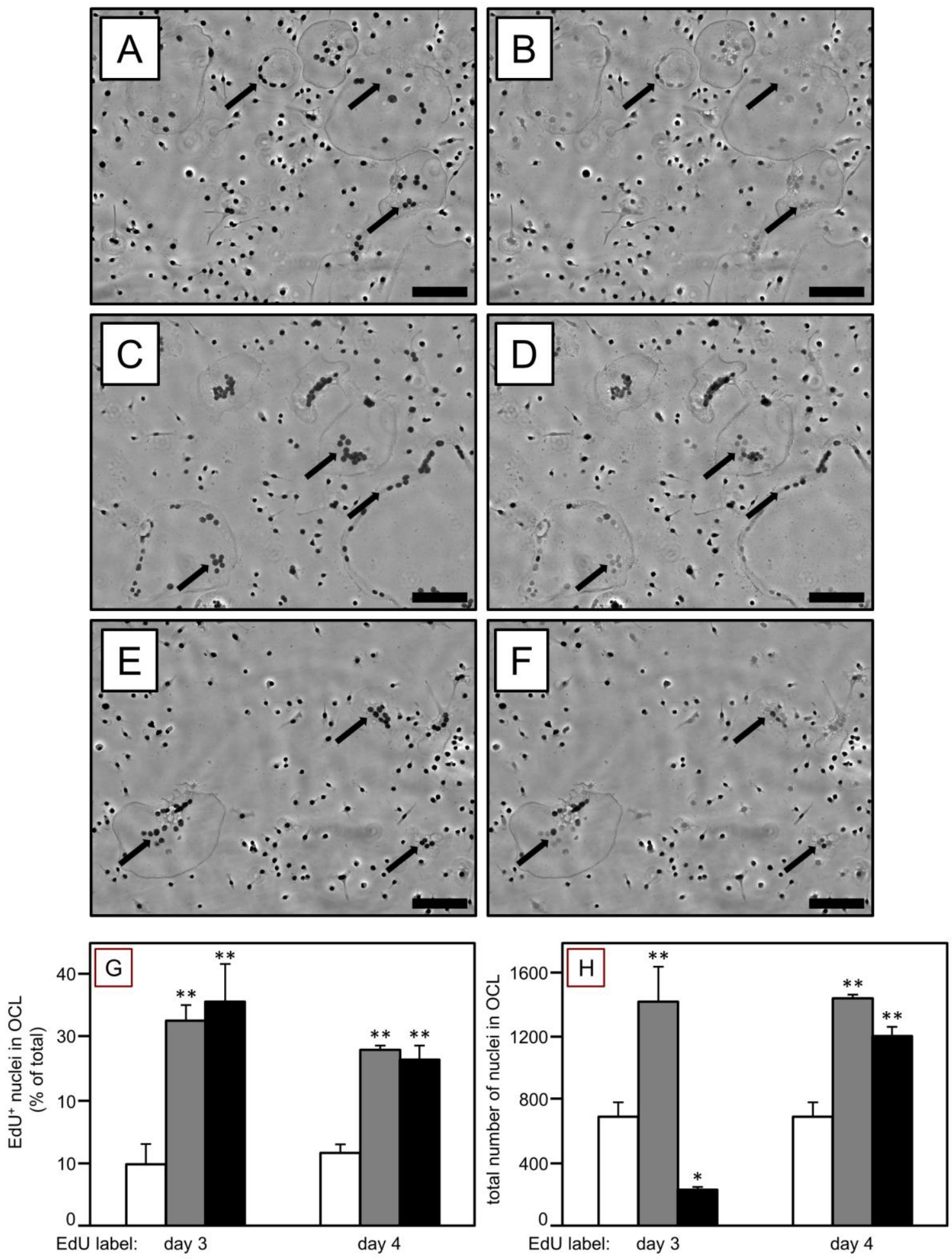